\title{
A critical review of manual therapy use for headache disorders: prevalence, profiles, motivations, communication and self-reported effectiveness
}

\author{
Craig S. Moore*, David W. Sibbritt and Jon Adams
}

\begin{abstract}
Background: Despite the expansion of conventional medical treatments for headache, many sufferers of common recurrent headache disorders seek help outside of medical settings. The aim of this paper is to evaluate research studies on the prevalence of patient use of manual therapies for the treatment of headache and the key factors associated with this patient population.
\end{abstract}

Methods: This critical review of the peer-reviewed literature identified 35 papers reporting findings from new empirical research regarding the prevalence, profiles, motivations, communication and self-reported effectiveness of manual therapy use amongst those with headache disorders.

Results: While available data was limited and studies had considerable methodological limitations, the use of manual therapy appears to be the most common non-medical treatment utilized for the management of common recurrent headaches. The most common reason for choosing this type of treatment was seeking pain relief. While a high percentage of these patients likely continue with concurrent medical care, around half may not be disclosing the use of this treatment to their medical doctor.

Conclusions: There is a need for more rigorous public health and health services research in order to assess the role, safety, utilization and financial costs associated with manual therapy treatment for headache. Primary healthcare providers should be mindful of the use of this highly popular approach to headache management in order to help facilitate safe, effective and coordinated care.

Keywords: Headache, Migraine, Tension headache, Cervicogenic headache, Manual therapy, Physical therapy, Chiropractic, Osteopathy, Massage

\section{Background}

The co-occurrence of tension headache and migraine is very high [1]. Respectively, they are the second and third most common disorders worldwide with migraine ranking as the seventh highest specific cause of disability globally [2] and the sixteenth most commonly diagnosed condition in the US [3]. These common recurrent headache disorders place a considerable burden upon the personal health, finances and work productivity of sufferers [3-5]

\footnotetext{
* Correspondence: Craig.S.Moore@student.uts.edu.au; craigsmoore@mac.com University of Technology Sydney, Faculty of Health, Building 10, Level 8, 235-253 Jones St, Ultimo, Sydney NSW, 2007, Australia
}

with migraine further complicated by an association with cardiovascular and psychiatric co-morbidities [6, 7].

Preventative migraine drug treatments include analgesics, anticonvulsants, antidepressants and beta-blockers. Preventative drug treatments for tension-type headaches can include analgesics, NSAIDs, muscle relaxants and botulinum toxin as well as anticonvulsants and antidepressants. While preventative drug treatments are successful for a significant proportion of sufferers, headache disorders are still reported as under-diagnosed and under-treated within medical settings [8-16] with other studies reporting sufferers can cease continuing with preventative headache medications long-term $[9,17]$. 
There is a number of non-drug approaches also utilized for the prevention of headaches. These include psychological therapies such as cognitive behavioral therapy, relaxation training and EMG (electromyography) biofeedback. In addition, there is acupuncture, nutritional supplementation (including magnesium, B12, B6, and Coenzyme Q10) and physical therapies. The use of physical therapies is significant, with one recent global survey reporting physical therapy as the most frequently used 'alternative or complementary treatment' for headache disorders across many countries [18]. One of the most common physical therapy interventions for headache management is manual therapy (MT), [19-21] which we define here as treatments including 'spinal manipulation (as commonly performed by chiropractors, osteopaths, and physical therapists), joint and spinal mobilization, therapeutic massage, and other manipulative and body-based therapies' [22].

Positive results have been reported in many clinical trials comparing MT to controls [23-27], other physical therapies [28-30] and aspects of medical care [31-34]. More high quality research is needed however to assess the efficacy of MT as a treatment for common recurrent headaches. Recent systematic reviews of randomized clinical trials of MT for the prevention of migraine report a number of significant methodological shortcomings and the need for more high quality research before any firm conclusions can be made [35, 36]. Recent reviews of MT trials for tension-type headache and cervicogenic headache are cautious in reporting positive outcomes and the strong need for further robust research [37-41]. Despite the limited clinical evidence there has been no critical review of the significant use of MT by headache populations.

\section{Methods}

The aim of this study is to report from the peerreviewed literature; 1) the prevalence of MT use for the treatment of common recurrent headaches and 2) factors associated with this use across several key themes. The review further identifies key areas worthy of further research in order to better inform clinical practice, educators and healthcare policy within this area.

\section{Design}

A comprehensive search of peer-reviewed articles published in English between 2000 and 2015 reporting new empirical research findings of key aspects of MT use among patients with migraine and non-migraine headache disorders was undertaken. Databases searched were MEDLINE, AMED, CINAHL, EMBASE and EBSCO. The key words and phrases used were: 'headache, 'migraine, 'primary headache,' 'cephalgia, 'chronic headache' AND 'manual therapy,' 'spinal manipulation,' 'manipulative therapy', 'spinal mobilization', 'chiropractic', 'osteopathy', 'massage, 'physical therapy' or 'physiotherapy' AND then 'prevalence,' 'utilization' or 'profile' was used for additional searches against the previous terms. The database search was accompanied by a hand search of prominent peer-reviewed journals. All authors accessed the reviewed literature (data) and provided input to analysis.

Due to the focus of the review, literature reporting randomized control trials and similar clinical research designs were excluded as were articles identified as letters, correspondence, editorials, case reports and commentaries. Further searches were undertaken of the bibliographies in the identified publications. All identified articles were screened and only those reporting new empirical findings on MT use for headache in adults were included in the review. Articles identified and selected for the review were research manuscripts mostly within epidemiological and health economics studies. The review includes papers reporting MT use pooled with the use of other therapies, but only where MT patients comprised a large proportion (as stated) of the included study population. Results were imported into Endnote X7 and duplicates removed.

\section{Search outcomes, analyses and quality appraisal}

Figure 1 outlines the literature search process. The initial search identified 3286 articles, 35 of which met the inclusion criteria. Information from each article was organized into a review table (Table 1) to summarise the findings of the included papers. Information is reported under two selected headache groups and within each individual MT profession - chiropractic, physiotherapy, osteopathy and massage therapy - where sufficient detail was available.

An appraisal of the quality of the articles identified for review was conducted using a quality scoring system (Table 2) developed for the critical appraisal of health literature used for prevalence and incidence of health problems [42] adapted from similar studies [43-45]. This scoring system was applicable to the majority of study designs involving surveys and survey-based structured interviews (29 of the 35 papers) but was not applicable to a small number of included studies based upon clinical records, secondary analysis or practitioner characteristics.

Two separate authors (CM and JA) independently searched and scored the articles. Score results were compared and any differences were further discussed and resolved by all the authors. The quality score of each relevant article is reported in Table 3.

\section{Results}

The key findings of the 35 articles were grouped and evaluated using a critical review approach adapted from 


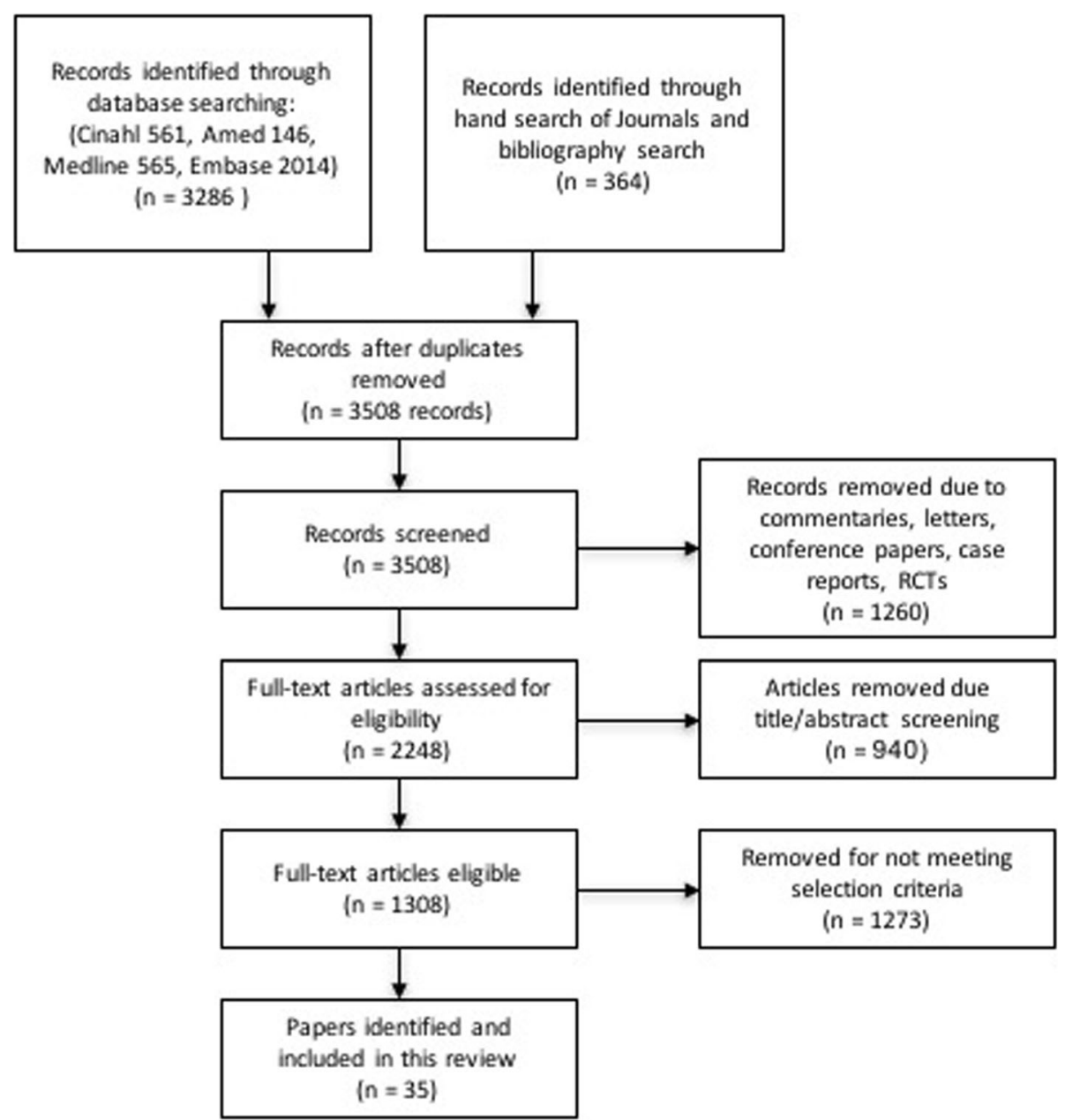

Fig. 1 Flow chart of study selection

previous research [46, 47]. Based on the limited information available for other headache types, prevalence findings are reported within one of two categories - either as 'migraine' for papers reporting studies where the population was predominately or entirely made up of migraine patients or as 'headache' for papers where the study population was predominately other headache types (including tension-type headaches, cluster headaches, cervicogenic headache) and/or where the headache type was not clearly stated. Ten papers reported findings examining prevalence rates for the 'migraine' category alone, 18 papers reported findings examining prevalence for the 'headache' category alone and 3 papers reported findings for both categories. Based on the nature of the information available, prevalence use was categorised by manual therapy providers. The extracted data was then analysed and synthesized into four thematic categories: prevalence; profile and motivations for MT use; concurrent use and order of use of headache providers; and selfreported evaluation of MT treatment outcomes.

\section{Prevalence of MT use}

Thirty-one of the reviewed articles with a minimum sample size $(>100)$ reported findings regarding prevalence of MT use. The prevalence of chiropractic use for those with migraine ranged from 1.0 to $36.2 \%$ (mean: $14.4 \%)$ within the general population [19-21, 48-52] and from 8.9 to $27.1 \%$ (mean: $18.0 \%$ ) within headacheclinic patient populations $[53,54]$. The prevalence of chiropractic use for those reported as headache ranged from 4 to $28.0 \%$ (mean: $12.9 \%$ ) within the general population [20, 48, 51, 55-57]; ranged from 12.0 to $22.0 \%$ (mean: 18.6\%) within headache/pain clinic patient populations [58-60] and from 1.9 to $45.5 \%$ (mean: 9.8\%) within chiropractic patient populations [61-69].

The prevalence use of physiotherapy for those with migraine ranged from 9.0 to $57.0 \%$ (mean: $24.7 \%$ ) within the general population $[19,20,48,52]$ and from 4.9 to $18.7 \%$ (mean: 11.8\%) within headache-clinic patient populations $[54,70]$. The prevalence use of physiotherapy for those reported as headache ranged from 12.2 to $52.0 \%$ (mean: 


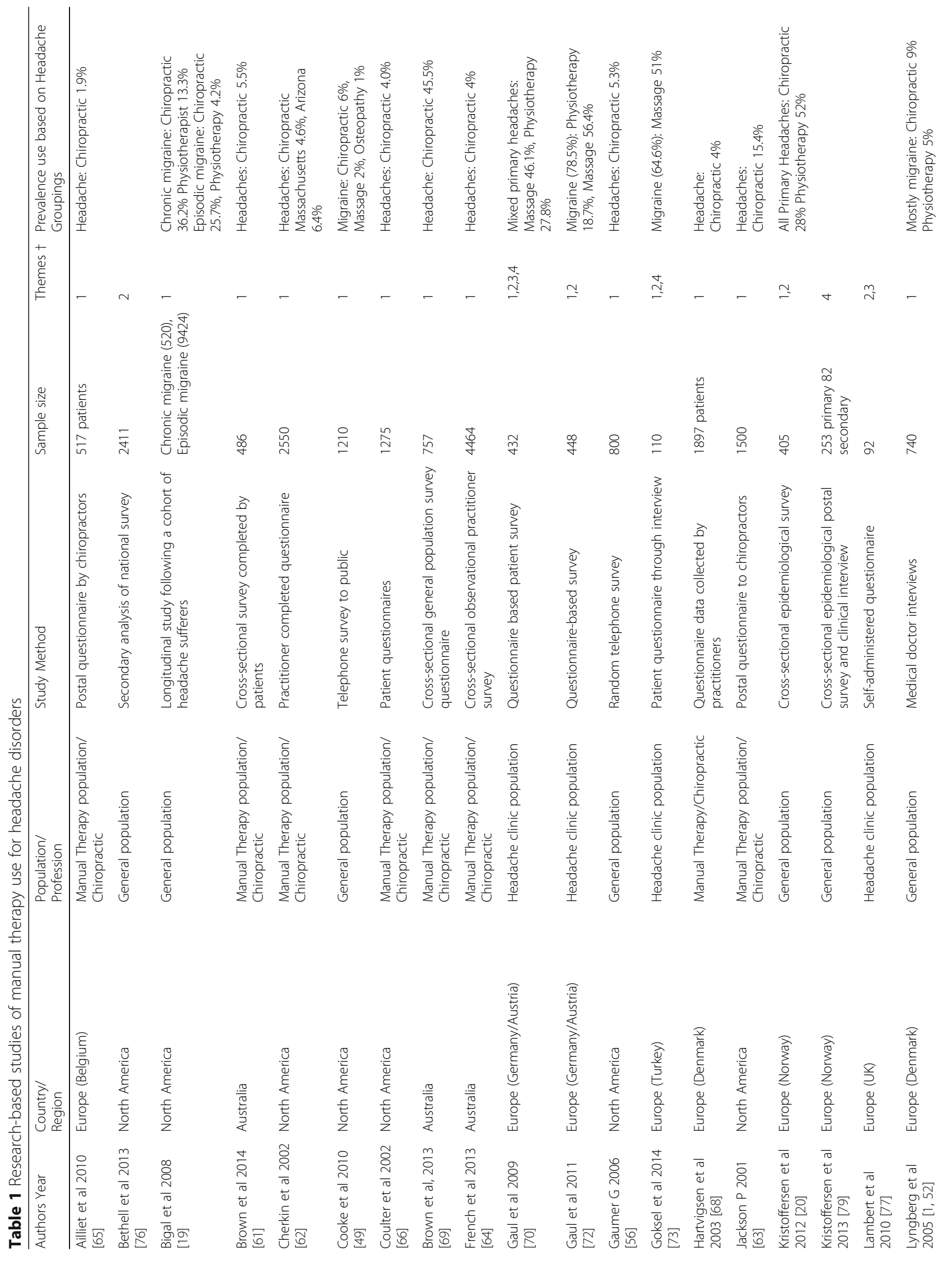




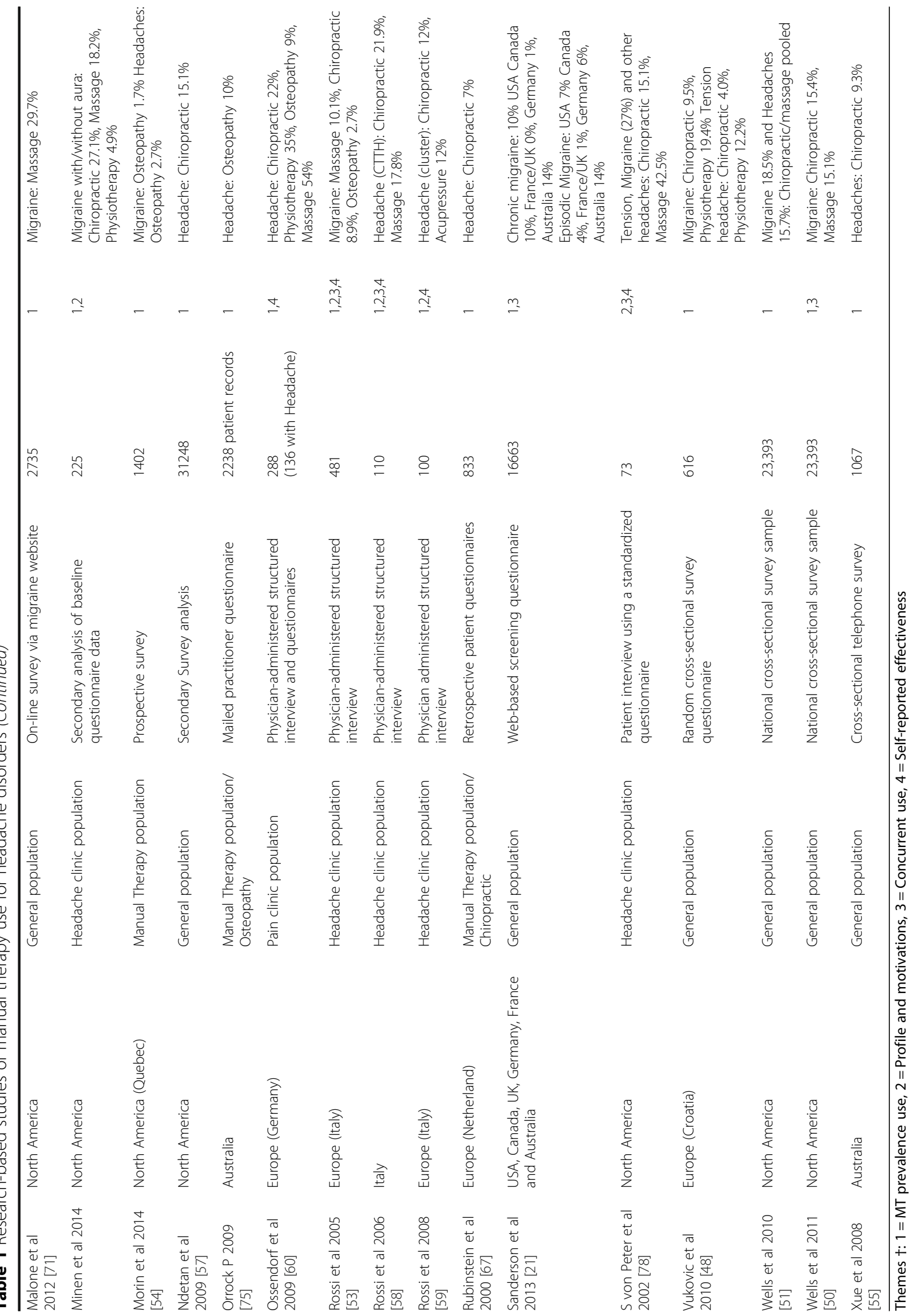


Table 2 Description of quality criteria and scoring for selected studies

\begin{tabular}{|c|c|}
\hline Dimensions of Quality Assessment & Points Awarded $\dagger$ \\
\hline \multicolumn{2}{|l|}{ Methodology } \\
\hline $\begin{array}{l}\text { A. Sampling strategy reported/ } \\
\text { appropriate to study design }\end{array}$ & 1 \\
\hline B. Sample size $>100$ & 1 \\
\hline C. Response rate $>75 \%$ & 1 \\
\hline $\begin{array}{l}\text { D. Low recall bias (prospective } \\
\text { data collection or retrospective data } \\
\text { collection within past } 12 \text { months) }\end{array}$ & 1 \\
\hline \multicolumn{2}{|l|}{ Reporting of Participants characteristics } \\
\hline $\begin{array}{l}\text { E. Classification of migraine or headache } \\
\text { type(s) reported }\end{array}$ & 1 \\
\hline F. Age and sex & 1 \\
\hline G. Ethnicity & 1 \\
\hline $\begin{array}{l}\text { H. Indicator of socioeconomic status } \\
\text { (income, education) }\end{array}$ & 1 \\
\hline \multicolumn{2}{|l|}{ Reporting of relevant MT factors } \\
\hline I. Reporting of MT use for headache & 1 \\
\hline J. Reporting of MT financial costs & 1 \\
\hline
\end{tabular}

$32.1 \%)$ within the general population $[20,48]$ and from 27.8 to $35.0 \% \%$ (mean: $31.4 \%$ ) within headache/pain clinic populations $[60,70]$.

Massage therapy use for those with migraine ranged from 2.0 to $29.7 \%$ (mean: $15.6 \%$ ) within the general population $[49,50,71]$ and from 10.1 to $56.4 \%$ (mean: $33.9 \%$ ) within headache-clinic populations [53, 54, 72, 73]. Massage/acupressure use for those reported as headache within headache/pain clinic patient populations ranged from 12.0 to $54.0 \%$ (mean: $32.5 \%$ ) [58-60, 70].

Osteopathy use for those with migraine was reported as $1 \%$ within the general population [49]; as $2.7 \%$ within a headache-clinic patient population [53] and as $1.7 \%$ within an osteopathy patient population [74]. For headache the prevalence was $9 \%$ within a headache/pain clinic population [60] and ranged from 2.7 to $10.0 \%$ (mean: $6.4 \%$ ) within osteopathy patient populations $[74,75]$.

The combined prevalence rate of MT use across all MT professions for those with migraine ranged from 1.0 to $57.0 \%$ (mean: $15.9 \%$ ) within the general population; ranged from 2.7 to $56.4 \%$ (mean: 18.4\%) within headache-clinic patient populations and was reported as $1.7 \%$ in one MT patient population. The combined prevalence rate of MT use across all MT professions for those reported as headache ranged from 4.0 to $52.0 \%$ (mean: 17.7\%) within the general population; ranged from 9.0 to $54.0 \%$ (mean: $32.3 \%$ ) within headache-clinic patient populations and from 1.9 to $45.5 \%$ (mean: $9.25 \%$ ) within MT patient populations.

\section{Profile and motivations for MT use}

While patient socio-demographic profiles were not reported within headache populations that were exclusively using MT, several studies report these findings where MT users made up a significant percentage of the non-medical headache treatments utilized by the study population (range 40\% - 86\%: mean 63\%). While findings varied for level of income $[58,70]$ and level of education, [70, 72, 73] this patient group were more likely to be older [70, 72], female [20], have a higher rate of comorbid conditions $[58,70,76]$ and a higher rate of previous medical visits $[20,58,70]$ when compared to the non-user group. Overall, this group were reported to have a higher level of headache chronicity or headache disability than non-users [20, 54, 58, 70, 72, 77].

Several studies within headache-clinic populations report patient motivations for the use of complementary and alternative headache treatments where MT users made up a significant proportion of the study population (range $40 \%$ - 86\%: mean 63\%) [58, 70, 72, 78]. From these studies the most common motivation reported by study patients was 'seeking pain relief' for headache which accounted for $45.4 \%$ - 84.0\% (mean: $60.5 \%$ ) of responses. The second most common motivation was patient concerns regarding the 'safety or side effects' of medical headache treatment, accounting for $27.2 \%$ - 53.0\% (mean: $43.8 \%$ ) of responses [58, 70, 72]. 'Dissatisfaction with medical care' accounted for $9.2 \%-35.0 \%$ (mean: $26.1 \%$ ) of responses [58, 70, 72].

A limited number of reviewed papers (all from Italy) report on the source of either the referral or recommendation to MT for headache treatment $[53,58,59]$. From these studies, referral from a GP to a chiropractor ranged from 50.0 to $60.8 \%$ (mean: $55.7 \%$ ), while referral from friends/ relatives ranged from 33.0 to $43.8 \%$ (mean: $38.7 \%$ ) and selfrecommendation ranged from 0 to $16.7 \%$ (mean: $5.6 \%$ ). For massage therapy, referral from a GP ranged from 23.2 to $50.0 \%$ (mean: $36.6 \%$ ), while referral from friends/relatives ranged from 38.4 to $42.3 \%$ (mean: $40.4 \%$ ) and selfrecommendation ranged from 7.7 to $38.4 \%$ (mean: $23.1 \%$ ). For acupressure, referral from a GP ranged from 33.0 to 50.0\% (mean: $41.5 \%$ ), while referral from friends/relatives was reported as $50 \%$ and self-recommendation ranged from 0 to $16.6 \%$ (mean: $8.3 \%$ ). One study reported findings for osteopathy where referral from both GP's and friends/ relatives was reported as $42.8 \%$ and self-recommendation was reported as $14.4 \%$. Overall, the highest proportion of referrals within these studies was from GPs to chiropractors for chronic tension-type headache (56.2\%), cluster headache (50\%) and migraine (60.8\%).

\section{Concurrent use and order of use of headache providers and related communication of MT users}

Several studies report on the concurrent use of medical headache management with complementary and alternative 
Table 3 Quality score for selected studies

\begin{tabular}{|c|c|c|c|c|}
\hline \multicolumn{5}{|c|}{ Dimensions of Quality Assessment } \\
\hline Authors/Year & Methodology & Participant characteristics & Reporting of MT use & Total score \\
\hline Ailliet et al, 2010 [65] & $A, B, C$ & $\mathrm{~F}, \mathrm{H}$ & I & 6 \\
\hline Bigal et al, 2008 [19] & $A, B, C, D$ & $E, F, G, H$ & & 8 \\
\hline Brown et al, 2013 [69] & $A, B, C, D$ & $\mathrm{~F}, \mathrm{H}$ & & 6 \\
\hline Brown et al, 2014 [61] & $A, B, C, D$ & $F, G, H$ & । & 8 \\
\hline Cherkin et al, 2002 [62] & $A, B, C, D$ & $F, G$ & । & 7 \\
\hline Cooke et al, 2010 [49] & $A, B, D$ & $E, F$ & & 5 \\
\hline Coulter et al, 2002 [66] & $A, B, D$ & $F, G, H$ & & 6 \\
\hline French et al, 2013 [64] & $A, B, D$ & $F, G, H$ & । & 7 \\
\hline Gaul et al, 2009 [70] & $A, B, D$ & $E, F, G, H$ & । & 8 \\
\hline Gaul et al, 2011 [72] & $A, B, D$ & $E, F, H$ & । & 7 \\
\hline Gaumer G, 2006 [56] & $A, B, D$ & $\mathrm{~F}, \mathrm{H}$ & & 5 \\
\hline Goksel et al, 2014 [73] & $A, B, D$ & $E, F, H$ & I & 7 \\
\hline Hartvigsen el al, 2003 [68] & $A, B, C, D$ & & & 4 \\
\hline Kristofferson et al, 2012 [20] & $A, B$ & $E, F, G$ & । & 6 \\
\hline Kristoffersen et al, 2013 [79] & $A, B, D$ & $E, F$ & । & 6 \\
\hline Lambert et al, 2010 [77] & $A, D$ & $F, G, H$ & I & 6 \\
\hline Lyngberg et al, 2005 [1, 52] & $A, B, C, D$ & $E, F$ & & 6 \\
\hline Malone et al, 2015 [71] & $B, C, D$ & $\mathrm{~F}$ & & 4 \\
\hline Ossendorf et al, 2009 [60] & $A, B, C, D$ & $\mathrm{~F}, \mathrm{H}$ & I & 7 \\
\hline Rossi et al, 2005 [53] & $A, B, D$ & $\mathrm{E}, \mathrm{F}, \mathrm{H}$ & I & 7 \\
\hline Rossi et al, 2006 [58] & $A, B, D, E, F, H$ & & । & 7 \\
\hline Rossi et al, 2008 [59] & $A, B, C, D$ & $E, F, H$ & & 7 \\
\hline Rubinstein et al, 2000 [67] & $A, B, C, D$ & $\mathrm{~F}, \mathrm{H}$ & & 6 \\
\hline Sanderson et al, 2013 [21] & $A, B, C, D$ & $E, F, G, H$ & & 8 \\
\hline S von Peter et al, 2002 [78] & C, D & $E, F, G, H$ & I & 7 \\
\hline Vukovic et al, 2010 [48] & $A, B, C, D$ & $E, F$ & & 6 \\
\hline Wells et al, 2010 [51] & $A, B, D$ & $F, G, H$ & & 6 \\
\hline Wells et al, 2011 [50] & $A, B, D$ & $\mathrm{~F}, \mathrm{G}, \mathrm{H}$ & I & 7 \\
\hline Xue et al, 2008 [55] & $A, B, D$ & $F, G, H$ & & 6 \\
\hline
\end{tabular}

Key: A-Sampling reported, B-Sample size $>100$, C-Response rate $>75 \%$, D-Low recall bias, E-Classification of headache type, F-Age and sex, G-Ethnicity, H-Socioeconomic status Scoring: 1-4 poor quality, 5-6 low quality, 7-8 moderate quality, 9-10 high quality

therapies. In those studies where the largest percentage of the patient population were users of MT's (range 57.0\% 86.4\%: mean $62.8 \%$ ), [58, 70, 78] concurrent use of medical care ranged between $29.5 \%$ and $79.0 \%$ (mean: $60.0 \%$ ) of the headache patient population.

These studies further report on the level of patient nondisclosure to medical providers regarding the use of MT for headache. Non-disclosure ranged between 25.5 and $72.0 \%$ (mean: $52.6 \%$ ) of the patient population, with the most common reason for non-disclosure reported as the doctor 'never asking,' ranging from 37.0 to $80.0 \%$ (mean: $58.5 \%$ ). This was followed by a patient belief that 'it was not important for the doctor to know' or 'none of the doctor's business, ranging from 10.0 to $49.8 \%$ (mean: $30.0 \%)$. This was followed by a belief that either 'the doctor would not understand' or 'would discourage' these treatments, ranging from 10.0 to $13.0 \%$ (mean: 11.5\%) [53, 77].

One large international study reported the ordering of the typical provider of headache care by comparing findings between several countries for migraine patients [21]. Primary care providers followed by neurologists were reported as the first and second providers for migraine treatment for nearly all countries examined. The only exception was Australia, where those with chronic migraine selected chiropractors as typical providers at equal frequency to neurologists ( $14 \%$ for both) while 
those with episodic migraine selected chiropractors at a greater frequency to neurologists (13\% versus $5 \%$ ). Comparatively, chiropractors were selected as the typical provider for those with chronic migraine by $10 \%$ in USA and Canada, 1\% in Germany and 0\% for UK and France. Chiropractors were selected as the typical provider for those with episodic migraine by $7 \%$ in USA, $6 \%$ in Germany, $4 \%$ in Canada and by $1 \%$ in both the UK and France.

\section{Self-reported effectiveness of MT treatment outcomes}

Several headache and pain-clinic population studies provide findings for the self-reported effectiveness of MT headache treatment. For chiropractic, patient self-reporting of partially effective or fully effective headache relief ranged from 27.0 to $82.0 \%$ (mean: $45.0 \%$ ) [53, 58-60, 78]. For massage therapy, patient self-reporting of partially effective or fully effective headache relief ranged from 33.0 to $64.5 \%$ (mean: 45.2\%)[53, 58, 60, 73, 78], and for acupressure this ranged from 33.4 to $50.0 \%$ (mean: $44.5 \%$ ) [53, 58, 59]. For osteopathy and physiotherapy, one study reported effectiveness as 17 and $36 \%$ respectively [60].

When results are combined across all MT professions the reporting of MT as either partially or fully effective ranged from 17.0 to $82.0 \%$ (mean $42.5 \%$ ) [53, 58-60, 73, 78]. In addition, one general population study provides findings for the self-reported effectiveness for chiropractic and physiotherapy at 25.6 and $25.1 \%$ respectively for those with primary chronic headache and 38 and $38 \%$ respectively for those with secondary chronic headache [79].

\section{Discussion}

This paper provides the first critical integrative review on the prevalence and key factors associated with the use of MT treatment for headaches within the peer-reviewed literature. While study methodological limitations and lack of data prevent making strong conclusions, these findings raise awareness of issues of importance to policy-makers, educators, headache providers and future research.

Our review found that MT use was generally higher within medical headache-clinic populations when compared to general populations. However, the use of individual MT providers does vary between different regions and this is likely due to a number of factors including variation in public access, healthcare funding and availability of MT providers. For example, the use of physiotherapy for some headache types may be relatively higher in parts of Europe [20,60] while the use of chiropractors for some headache types may be relatively higher in Australia and the USA [19, 21]. Overall, the prevalence use of MT for headache appears to be substantial and likely to be the most common type of physical therapy utilized for headache in many countries [19-21, 49]. More high quality epidemiological studies are needed to measure the prevalence of MT use across different headache types and sub-types, both within the general population and clinical populations.

Beyond prevalence, data is more limited regarding who, how and why headache patients seek MT. From the information available however, the healthcare needs of MT headache patients may be more complex and multi-disciplinary in nature compared to those under usual medical care alone. Socio-demographic findings suggest that users of MT and other complementary and alternative therapies have a higher level of headache disability and chronicity compared to non-users. This finding may correlate with the higher prevalence of MT users within headache-clinic populations and a history of more medical appointments. This may also have implications for future MT trial designs both in terms of the selection of trial subjects from inside versus outside MT clinical settings and the decision to test singular MT interventions versus $\mathrm{MT}$ in combination with other interventions.

Limited information suggests that a pluralistic approach toward the use of medical and non-medical headache treatments such as MT is common. While findings suggest MT is sought most often for reasons of seeking headache relief, the evidence to support the efficacy of MT for headache relief is still limited. MT providers must remain mindful of the quality of the evidence for a given intervention for a given headache disorder and to inform patients where more effective or safer treatment interventions are available. More research is needed to assess these therapies individually and through multimodal approaches and for studies to include long-term follow-up.

Information limited to Italy, suggests referral from GPs for MT headache treatment can be common in some regions, while this is less likely to widespread given the issue of patient non-disclosure to medical doctors regarding the use of this treatment in other studies. High quality healthcare requires open and transparent communication between patients and providers and between the providers themselves. Non-disclosure may adversely influence medical management should unresponsive patients require further diagnostic investigations [80] or the implementation of more effective approaches to headache management [81] or prevents discussion in circumstances where MT may be contraindicated [82]. Primary headache providers may benefit from paying particular attention to the possibility of non-disclosure of non-medical headache treatments. Open discussion between providers and patients about the use of MT for headache and the associated outcomes may improve overall patient care.

\section{Future research}

Despite the strong need for more high quality research to assess the efficacy of MT as a treatment for headache, 
the substantial use of MT brings attention to the need for more public health and health services research within this area of headache management. The need for this type of research was identified in a recent global report on the use of headache-related healthcare resources [18]. Furthering this information can lead to improvements in healthcare policy and the delivery of healthcare services.

The substantial use of physical therapies such as MT has been under-reported within many of the national surveys reporting headache-related healthcare utilization $[3,5,83-85]$. Regardless, the role of physical therapies in headache management continues to be assessed, often within mainstream and integrated headache management settings [86-89]. Continuing this research may further our understanding of the efficacy and outcomes associated with a more multidisciplinary approach to headache management.

Further to this is the need for more research to understand the healthcare utilization pathways associated with those patients who use MT in their headache management. Little is known about the sociodemographic background, types of headaches, level of headache disability and comorbidities more common to this patient population. In turn, such information can provide insights that may be valuable to provider clinical decision-making and provider education.

\section{Limitations}

The design and findings of our review has a number of limitations. The design of the review was limited by a search within English language journals only. As a result, some research on this topic may have been missed. While the quality scoring system adopted for this review requires further validation, the data we collected was limited by the low to moderate quality of available papers which averaged 6.4 out of 10 points (Table 3 ). The low scoring was largely due to significant methodological issues and the small sample size associated with much of the collected papers. Much of the data on this topic was heterogeneous in nature (telephone, postal surveys and face-to-face interviews). There was a lack of validated practitioner and patient questionnaires to report findings, such as for questions on prevalence, where the time frames utilized varied between 'currently', 'last 12 months' and 'ever'.

Data on the prevalence of MT use for headache was limited particularly within individual MT provider populations when compared to data found within the general population and headache-clinic populations. Many studies assessed the use of MT for headache without identifying headache types. Only one study inside an MT population had reported the percentage of patients attending for reasons of migraine alone (osteopathy). The prevalence of MT use for headache was reported most within chiropractic patient population studies, however information was limited on the types of headache. We found no studies reporting the prevalence of headache patients within physiotherapy or massage therapy patient populations using our search terms.

A lack of data for some themes necessitated providing findings pooled with users of other non-medical headache providers. Data within many geographical regions was very limited with the most limited data was on the source of referral to MT headache providers (three papers from Italy only). These limitations support the call for more research to be focused exclusively within MT populations and different regional areas before stronger conclusions can be drawn.

\section{Conclusion}

The needs of those with headache disorders can be complex and multi-disciplinary in nature. Beyond clinical research, more high quality public health and health services research is needed to measure and examine a number of issues of significance to the delivery and use of MT's within headache management. With unmet needs still remaining for many who suffer recurrent headaches, clinicians should remain cognizant of the use of MT's and remain open to discussing this approach to headache management in order to ensure greater safety, effectiveness and coordination of headache care.

\section{Abbreviations \\ MT: Manual therapy; EMG: Electromyography}

\section{Acknowledgements}

Not applicable.

\section{Funding}

This research received no specific grant from any funding agency in the public, commercial or not-for-profit sectors while the first author on this paper receives a PhD scholarship made available by the Australian

Chiropractors' Association.

Availability of data and materials

Not applicable (all data is reported in article).

\section{Authors' contributions}

CM, JA and DS designed the paper. CM carried out the literature search, data collection and selection. CM and DS provided the analysis and interpretation. $\mathrm{CM}$ and JA wrote the drafts. All authors contributed to the critical review

and intellectual content. All authors read and approved the final manuscript.

\section{Competing interests}

The authors declare that they have no competing interests.

Consent for publication

Not applicable.

Ethics approval and consent to participate Not applicable.

\section{Publisher's Note}

Springer Nature remains neutral with regard to jurisdictional claims in published maps and institutional affiliations. 


\section{Received: 2 August 2016 Accepted: 13 March 2017}

Published online: 24 March 2017

\section{References}

1. Lyngberg AC, Rasmussen BK, Jørgensen T, Jensen R. Has the prevalence of migraine and tension-type headache changed over a 12-year period? a Danish population survey. Eur J Epidemiol. 2005;20:243-9.

2. Vos T, Flaxman A, Naghavi M. Years lived with disability (YLDs) for 1160 sequelae of 289 diseases and injuries 1990-2010: a systematic analysis for the global burden of disease study 2010. Lancet. 2012;380:2163-96.

3. Burch RC, Loder S, Loder E, Smitherman TA. The prevalence and burden of migraine and severe headache in the united states: updated statistics from government health surveillance studies. Headache. 2015:55:21-34.

4. Lanteri-Minet M. Economic burden and costs of chronic migraine. Curr Pain Headache Rep. 2014;18:385.

5. Bloudek L, Stokes M, Buse D, Wilcox T, Lipton R, Goadsby P, Varon S, Blumenfeld A, Katsarava Z, Pascual J, et al. Cost of healthcare for patients with migraine in five European countries: results from the international burden of migraine study (IBMS). J Headache Pain. 2012;13:361-78.

6. Antonaci F, Nappi G, Galli F, Manzoni GC, Calabresi P, Costa A. Migraine and psychiatric comorbidity: a review of clinical findings. J Headache Pain. 2011;12:115-25.

7. Kurth T, Chabriat H, Bousser M-G. Migraine and stroke: a complex association with clinical implications. Lancet Neurol. 2012;11:92-100.

8. Lipton R, Goadsby P, Sawyer J, Blakeborough P, Stewart W. Migraine: diagnosis and assessment of disability. Rev Contemp Pharmaco. 2000;11:63-73.

9. Diamond S, Bigal ME, Silberstein S, Loder E, Reed M, Lipton RB. Patterns of diagnosis and acute and preventive treatment for migraine in the united states: results from the American migraine prevalence and prevention study. Headache. 2007;47:355-63.

10. Lipton RB, Bigal ME, Diamond M, Freitag F, Reed M, Stewart WF. Migraine prevalence, disease burden, and the need for preventive therapy. Neurology. 2007:68:343-9.

11. Berger A, Bloudek LM, Varon SF, Oster G. Adherence with migraine prophylaxis in clinical practice. Pain Pract. 2012;12:541-9.

12. Peres MFP, Silberstein S, Moreira F, Corchs F, Vieira DS, Abraham N, GebelineMyers C. Patients' preference for migraine preventive therapy. Headache. 2007; 47:540-5.

13. Nicholson RA, Rooney M, Vo K, O'Laughlin E, Gordon M. Migraine care among different ethnicities: Do disparities exist? Headache. 2006;46:754-65.

14. Lafata JE, Tunceli O, Cerghet M, Sharma KP, Lipton RB. The use of migraine preventive medications among patients with and without migraine headaches. Cephalalgia. 2010;30:97-104.

15. Cevoli S, D'Amico D, Martelletti P, Valguarnera F, Del Bene E, De Simone R, Sarchielli P, Narbone MC, Testa L, Genco S, et al. Underdiagnosis and undertreatment of migraine in Italy: a survey of patients attending for the first time 10 headache centres. Cephalalgia. 2009;29:1285-93.

16. Stark RJ, Valenti L, Miller GC. Management of migraine in Australian general practice. Med J Aust. 2007;187:142.

17. Lipton RB, Buse DC, Serrano D, Holland S, Reed ML. Examination of unmet treatment needs among persons with episodic migraine: results of the American migraine prevalence and prevention (AMPP) study. Headache. 2013:53:1300-11

18. WHO Lifting the Burden 2011: http://www.who.int/mental_health/management/ who_atlas_headache_disorders.pdf?ua=1. Retrieved 8 August 2015

19. Bigal ME, Serrano D, Reed M, Lipton RB. Chronic migraine in the population Burden, diagnosis, and satisfaction with treatment. Neurology. 2008;71:559-66.

20. Kristoffersen ES, Grande RB, Aaseth K, Lundqvist C, Russell MB. Management of primary chronic headache in the general population: the Akershus study of chronic headache. J Headache Pain. 2012;13:113-20.

21. Sanderson JC, Devine EB, Lipton RB, Bloudek LM, Varon SF, Blumenfeld AM, Goadsby PJ, Buse DC, Sullivan SD. Headache-related health resource utilisation in chronic and episodic migraine across six countries. J Neurol Neurosurg Psychiatry. 2013;84:1309-17.

22. Biology of Manual Therapies (R21) National Institute of Health, 2014: http:// grants.nih.gov/grants/guide/pa-files/PA-14-167.html Retrieved 11 August 2015

23. Marcus D, Scharff L, Mercer S, Turk D. Nonpharmacological treatment for migraine: incremental utility of physical therapy with relaxation and thermal biofeedback. Cephalalgia. 1998;18:266-72.

24. Lawler SP, Cameron LD. A randomized, controlled trial of massage therapy as a treatment for migraine. Ann Behav Med. 2006;32:50-9.
25. Tuchin PJ, Pollard H, Bonello R. A randomized controlled trial of chiropractic spinal manipulative therapy for migraine. J Manipulative Physiol Ther. 2000;23:91-5

26. Hoyt W, Shaffer F, Bard D, Benesler J, Blankenhorn G, Gray J, Hartman W, Hughes L. Osteopathic manipulation in the treatment of muscle-contraction headache. J Am Osteopath Assoc. 1979:78:322-5.

27. Jull G, Trott P, Potter H, Zito G, Niere K, Shirley D, Emberson J, Marschner I, Richardson C. A randomized controlled trial of exercise and manipulative therapy for cervicogenic headache. Spine (Phila Pa 1976). 2002;27:1835-43.

28. Haas M, Spegman A, Peterson D, Aickin M, Vavrek D. Dose-Response and Efficacy of Spinal Manipulation for Chronic Cervicogenic Headache: A Pilot Randomized Controlled Trial. Spine J. 2010;10:117-28.

29. Bove G, Nilsson N. Spinal manipulation in the treatment of episodic tensiontype headache: a randomized controlled trial. JAMA. 1998;280:1576-9.

30. Parker GB, Pryor DS, Tupling H. Why does migraine improve during a clinical trial? Further results from a trial of cervical manipulation for migraine. Aust N Z J Med. 1980;10:192-8.

31. Hsieh LL-C, Liou H-H, Lee L-H, Chen TH-H, Yen AM-F. Effect of acupressure and trigger points in treating headache: a randomized controlled trial. Am J Chin Med. 2010;38:1-14.

32. Boline P, Kassack K, Bronfort G, Nelson C, Anderson A. Spinal manipulation vs. amitriptyline for the treatment of chronic tension-type headaches: a randomized clinical trial. J Manipulative Physiol Ther. 1995;18:148-54.

33. Nelson CF, Bronfort G, Evans R, Boline P, Goldsmith C, Anderson AV. The efficacy of spinal manipulation, amitriptyline and the combination of both therapies for the prophylaxis of migraine headache. J Manipulative Physiol Ther. 1998;21:511-9.

34. Castien RF, Windt DA, Grooten A, Dekker J. Effectiveness of manual therapy for chronic tension-type headache: a pragmatic, randomised, clinical trial. Cephalalgia. 2011;31:133-43.

35. Chaibi A, Tuchin P, Russell M. Manual therapies for migraine: a systematic review. J Headache Pain. 2011;12:127-33.

36. Posadzki P, Ernst E. Spinal manipulations for the treatment of migraine: a systematic review of randomized clinical trials. Cephalalgia. 2011:31:964-70.

37. Posadzki P, Ernst E. Spinal manipulations for tension-type headaches: a systematic review of randomized controlled trials. Complement Ther Med. 2012;20:232-9.

38. Racicki S, Gerwin S, DiClaudio S, Reinmann S, Donaldson M. Conservative physical therapy management for the treatment of cervicogenic headache: a systematic review. J Man Manip Ther. 2013;21:113-24.

39. Chaibi A, Russell MB. Manual therapies for cervicogenic headache: a systematic review. J Headache Pain. 2012;13:351-9.

40. Chaibi A, Russell MB. Manual therapies for primary chronic headaches: a systematic review of randomized controlled trials. J Headache Pain. 2014;15:67.

41. Mesa-Jiménez JA, Lozano-López C, Angulo-Díaz-Parreño S, RodríguezFernández ÁL, De-la-Hoz-Aizpurua JL, Fernández-de-las-Peñas C. Multimodal manual therapy vs. pharmacological care for management of tension type headache: A meta-analysis of randomized trials. Cephalalgia. 2015;35:1323-32.

42. Loney PL, Chambers LW, Bennett KJ, Roberts JG, Stratford PW. Critical appraisal of the health research literature prevalence or incidence of a health problem. Chronic Dis Inj Can. 1998;19:170.

43. Fejer R, Kyvik KO, Hartvigsen J. The Prevalence of neck pain in the world population: a systematic critical review of the literature. Eur Spine. 2006;15:834-48

44. Bishop F, Prescott P, Chan Y, Saville J, von Elm E, Lewith G. Complementary medicine use by men with prostate cancer: a systematic review of prevalence studies. Prostate Cancer Prostatic Dis. 2011;14:1-13.

45. Adams J, Barbery G, Lui C-W. Complementary and alternative medicine use for headache and migraine: a critical review of the literature. Headache. 2013:53:459-73.

46. Adams J, Chi-Wai L, Sibbritt D, Broom A, Wardle J, Homer C. Attitudes and referral practices of maternity care professionals with regard to complementary and alternative medicine: an integrative review. J Adv Nurs. 2011;67:472-83.

47. Solomon D, Adams J. The use of complementary and alternative medicine in adults with depressive disorders. A critical integrative review. J Affect Disord. 2015;179:101-13.

48. Vuković V, Plavec D, Lovrencić Huzjan A, Budisić M, Demarin V. Treatment of migraine and tension-type headache in Croatia. J Headache Pain. 2010;11:227-34

49. Cooke $\sqcup$, Becker WJ. Migraine prevalence, treatment and impact: the canadian women and migraine study. Can J Neurol Sci. 2010;37:580-7. 
50. Wells RE, Bertisch SM, Buettner C, Phillips RS, McCarthy EP. Complementary and alternative medicine use among adults with migraines/severe headaches. Headache. 2011;51:1087-97.

51. Wells RE, Phillips RS, Schachter SC, McCarthy EP. Complementary and alternative medicine use among US adults with common neurological conditions. J Neurol. 2010;257:1822-31.

52. Lyngberg AC, Rasmussen BK, Jørgensen $T$, Jensen $R$. Secular changes in health care utilization and work absence for migraine and tension-type headache: a population based study. Eur J Epidemiol. 2005;20:1007-14.

53. Rossi P, Di Lorenzo G, Malpezzi MG, Faroni J, Cesarino F, Di Lorenzo C, Nappi G. Prevalence, pattern and predictors of use of complementary and alternative medicine (CAM) in migraine patients attending a headache clinic in Italy. Cephalalgia. 2005;25:493-506.

54. Minen MT, Seng EK, Holroyd KA. Influence of family psychiatric and headache history on migraine-related health care utilization. Headache. 2014;54:485-92.

55. Xue C, Zhang A, Lin V, Myers R, Polus B, Story D. Acupuncture, chiropractic and osteopathy use in Australia: a national population survey. BMC Public Health. 2008:8:105.

56. Gaumer G. Factors associated with patient satisfaction with chiropractic care: survey and review of the literature. J Manipulative Physiol Ther. 2006;29:455-62.

57. Ndetan HT, Bae S, Evans Jr MW, Rupert RL, Singh KP. Characterization of health status and modifiable risk behavior among United States adults using chiropractic care as compared with general medical care. J Manipulative Physiol Ther. 2009;32:414-22.

58. Rossi P, Di Lorenzo G, Faroni J, Malpezzi MG, Cesarino F, Nappi G. Use of complementary and alternative medicine by patients with chronic tensiontype headache: results of a headache clinic survey. Headache. 2006;46:622-31.

59. Rossi P, Torelli P, Di Lorenzo C, Sances G, Manzoni GC, Tassorelli C, Nappi G. Use of complementary and alternative medicine by patients with cluster headache: results of a multi-centre headache clinic survey. Complement Ther Med. 2008;16:220-7.

60. Ossendorf A, Schulte E, Hermann K, Hagmeister H, Schenk M, Kopf A, Schuh-Hofer S, Willich SN, Berghöfer A. Use of complementary medicine in patients with chronic pain. Eur J Integrative Med. 2009;1:93-8.

61. Brown BT, Bonello R, Fernandez-Caamano R, Eaton S, Graham PL, Green H. Consumer characteristics and perceptions of chiropractic and chiropractic services in Australia: results from a cross-sectional survey. J Manipulative Physiol Ther. 2014;37:219-29.

62. Cherkin DC, Deyo RA, Sherman KJ, Hart LG, Street JH, Hrbek A, Davis RB, Cramer E, Milliman B, Booker J, et al. Characteristics of visits to licensed acupuncturists, chiropractors, massage therapists, and naturopathic physicians. J Am Board Fam Med. 2002;15:463-72.

63. Jackson P. Summary of the 2000 ACA professional survey on chiropractic practice. J Am Chiro Assn. 2001;38:27-30.

64. French S, Charity M, Forsdike K, Gunn J, Polus B, Walker B. Chiropractic Observation and Analysis Study (COAST): providing an understanding of current chiropractic practice. Med J Aust. 2013;10:687-91.

65. Ailliet L, Rubinstein SM, de Vet HCW. Characteristics of chiropractors and their patients in Belgium. J Manipulative Physiol Ther. 2010;33:618-25.

66. Coulter I, Hurwitz E, Adams A, Genovese B, Hays R, Shekelle P. Patients using chiropractors in North America: who are they, and why are they in chiropractic care? Spine (Phila Pa 1976). 2002;27:291-8.

67. Rubinstein S, Pfeifle CE, van Tulder MW, Assendelft WJJ. Chiropractic patients in the Netherlands: A descriptive study. J Manipulative Physiol Ther. 2000;23:557-63.

68. Hartvigsen J, Bolding-Jensen O, Hviid H, Grunnet-Nilsson N. Danish chiropractic patients then and now - a comparison between 1962 and 1999. J Manipulative Physiol Ther. 2003;26:65-9.

69. Brown B, Bonello R, Fernandez-Caamano R, Graham P, Eaton S, Green H. Chiropractic in Australia : a survey of the general public. Chiropractic J Aust. 2013:43:85-92

70. Gaul C, Eismann R, Schmidt T, May A, Leinisch E, Wieser T, Evers S, Henkel K, Franz G, Zierz S. Use of complementary and alternative medicine in patients suffering from primary headache disorders. Cephalalgia. 2009;29:1069-78.

71. Malone CD, Bhowmick A, Wachholtz AB. Migraine: treatments, comorbidities, and quality of life, in the USA. J Pain Res. 2015;8:537-47.

72. Gaul C, Schmidt T, Czaja E, Eismann R, Zierz S. Attitudes towards complementary and alternative medicine in chronic pain syndromes: a questionnaire-based comparison between primary headache and low back pain. BMC Complement Altern Med. 2011;11:1-8.
73. Karakurum Goksel B, Coskun O, Ucler S, Karatas M, Ozge A, Ozkan S. Use of complementary and alternative medicine by a sample of Turkish primary headache patients. Agri Dergisi. 2014;26:1-7.

74. Morin C, Aubin A. Primary reasons for osteopathic consultation: a prospective survey in quebec. PLoS One. 2014;9:e106259.

75. Orrock PJ. Profile of members of the Australian osteopathic association: part 2 - the patients. Int J Osteopath Med. 2009:12:128-39.

76. Bethell C, Kemper KJ, Gombojav N, Koch TK. Complementary and conventional medicine use among youth with recurrent headaches. Pediatrics. 2013;132:e1173-e83.

77. Lambert TD, Morrison KE, Edwards J, Clarke CE. The use of complementary and alternative medicine by patients attending a UK headache clinic. Complement Ther Med. 2010;18:128-34.

78. von Peter S, Ting W, Scrivani S, Korkin E, Okvat H, Gross M, Oz C, Balmaceda C. Survey on the use of complementary and alternative medicine among patients with headache syndromes. Cephalalgia. 2002;22:395-400.

79. Kristoffersen ES, Aaseth K, Grande RB, Lundqvist C, Russell MB. Self-reported efficacy of complementary and alternative medicine: the Akershus study of chronic headache. J Headache Pain. 2013;13:113-20.

80. Sobri M, Lamont A, Alias N, Win M. Red flags in patients presenting with headache: clinical indications for neuroimaging. Br J Radiol. 2014; 76(908):532-35.

81. Carville S, Padhi S, Reason T, Underwood M, Group GD. Diagnosis and management of headaches in young people and adults: summary of NICE guidance. BMJ. 2012;345:e5765

82. Puentedura EJ, March J, Anders J, Perez A, Landers MR, Wallmann HW Cleland JA. Safety of cervical spine manipulation: are adverse events preventable and are manipulations being performed appropriately? a review of 134 case reports. J Man Manip Ther. 2012;20:66-74.

83. Becker C, Brobert GP, Almqvist PM, Johansson S, Jick SS, Meier CR. Migraine incidence, comorbidity and health resource utilization in the UK. Cephalalgia (Wiley-Blackwell). 2008;28:57-64.

84. Brandes $\mathrm{JL}$. Global trends in migraine care: results from the MAZE survey. CNS Drugs. 2002;16:13-8

85. Radtke A, Neuhauser H. Prevalence and burden of headache and migraine in Germany. Headache. 2009:49:79-89.

86. Zeeberg $\mathrm{P}$, Olesen J, Jensen R. Efficacy of multidisciplinary treatment in a tertiary referral headache centre. Cephalalgia (Wiley-Blackwell). 2005;25:1159-67.

87. Wallasch T-M, Angeli A, Kropp P. Outcomes of a headache-specific crosssectional multidisciplinary treatment program. Headache. 2012;52:1094-105.

88. Wallasch T-M, Hermann C. Validation of criterion-based patient assignment and treatment effectiveness of a multidisciplinary modularized managed care program for headache. J Headache Pain. 2012;13:379-87.

89. Gaul C, Visscher CM, Bhola R, Sorbi MJ, Galli F, Rasmussen AV, Jensen R. Team players against headache: multidisciplinary treatment of primary headaches and medication overuse headache. J Headache Pain. 2011:12:511-9.

\section{Submit your next manuscript to BioMed Central and we will help you at every step:}

- We accept pre-submission inquiries

- Our selector tool helps you to find the most relevant journal

- We provide round the clock customer support

- Convenient online submission

- Thorough peer review

- Inclusion in PubMed and all major indexing services

- Maximum visibility for your research

Submit your manuscript at www.biomedcentral.com/submit
) Biomed Central 